\title{
Differences in the Antibody Response to Human Immunodeficiency Virus-1 Envelope Glycoprotein (gp160) in Infected Laboratory Workers and Vaccinees
}

\author{
Seth H. Pincus, Katherine G. Messer, David H. Schwartz, " George K. Lewis, ${ }^{\star}$ Barney S. Graham, \\ William A. Blattner," and Greg Fisher \\ Laboratory of Microbial Structure and Function, Rocky Mountain Laboratories, National Institute of Allergy and Infectious Diseases, \\ National Institutes of Health, Hamilton, Montana 59840; *Johns Hopkins School of Public Health, Baltimore, Maryland 21205; \\ ${ }^{\ddagger}$ University of Maryland School of Medicine, Baltimore, Maryland 21201; ${ }^{\S}$ Vanderbilt University School of Medicine, Nashville, \\ Tennessee 37232; and "National Cancer Institute, Bethesda, Maryland 20892
}

\begin{abstract}
Studies of the immune response to the human immunodeficiency virus ( HIV) have been hampered by the antigenic diversity of the HIV envelope protein. In an effort to predict the efficacy of vaccination we have compared the systemic antienvelope antibody response in seronegative volunteers immunized with recombinant gp160 (either in vaccinia or as soluble protein produced in baculovirus) derived from the HTLV-IIIB strain of HIV-1 and in two laboratory workers accidentally infected with the same strain. 11 of 14 vaccinees responded to immunization by producing anti-gp160 of similar titer and the same isotype as that seen in the laboratory workers. Four vaccinees also had antibody to the principal neutralizing domain (V3 loop) that was comparable in titer with that seen in the laboratory workers, but the fine specificity of anti-V3 antibody was qualitatively different in the two groups. Antibody that can block the interaction between CD4 and gp120 was present at comparable levels in three vaccinees and the lab workers. Neutralizing antibody titers were markedly lower in the vaccinees than in the laboratory workers. In seven of the vaccinees, an immunodominant epitope was at amino acid 720-740. Analyses of monoclonal antibodies to this region indicate that they do not neutralize, bind to infected cells, nor function as immunotoxins. Although the anti-gp160 antibody response was of similar magnitude in both infected and vaccinated individuals, there were important qualitative differences. (J. Clin. Invest. 1993. 91:1987-1996.) Key words: HIV • AIDS • immunoglobulin • vaccine
\end{abstract}

\section{Introduction}

The development of an effective vaccine to prevent infection with HIV is a high priority for AIDS research. Several different subunit vaccines based upon the HIV envelope glycoprotein, gp160, have been tested in humans (1-3). Gp160 contains well-defined variable and constant regions located on extracellular (gp120) and transmembrane (gp41) domains. Although the gp 160-based subunit vaccines are immunogenic, the ability

Address reprint requests to Dr. Seth Pincus, Laboratory of Microbial Structure and Function, Rocky Mountain Laboratories, Hamilton, MT 59840.

Received for publication 19 June 1992 and in revised form $16 \mathrm{No}$ vember 1992.

The Journal of Clinical Investigation, Inc.

Volume 91, May 1993, 1987-1996 of the resulting immune response to protect humans against infection is not known. In vitro correlates of humoral immunity such as viral neutralization, inhibition of the interaction between the HIV envelope and its receptor (CD4), and epitope specificity may be predictors of protective antibody responses (4-8).

Evaluation of immune responses in vaccinees should include comparisons with those in infected individuals. Because natural infection results in a persistent exposure to a replicating antigen, it may be a most effective way to induce an appropriate and protective immune response (9). However, such analyses are complicated by the antigenic variability of HIV. Since the infecting strain of HIV is rarely known, sera from infected individuals are usually tested on heterologous laboratory strains of HIV. Some of the immunologically most important regions of gp 160 are located in the variable regions. Thus direct comparisons of vaccine responses and immunity arising in natural infection have not yet been performed.

Two laboratory workers have been identified who have been infected with the HTLV-IIIB/LAV strain of HIV (hereafter referred to as IIIB) (10). Many of the gp160 subunit vaccines utilize envelope glycoprotein derived from this same strain of HIV $(1-3,6)$. In this paper we compare the antigpl60 antibody responses in the laboratory workers with those from "high responder" vaccinees who were selected because they produced antibody titers comparable to those seen in the laboratory workers. The results indicate that, although antibody of similar titer and isotype was produced in vaccinees and lab workers, there were significant differences in the quality and fine specificity of the antibody response.

\section{Methods}

HIV strains. The vaccines used in this experiment express the envelope protein derived from the LAV (LAI) strain of HIV. The envelope protein of the molecularly cloned HIV isolate NL4-3 is also derived from LAV (11). The laboratory workers have been infected with the HTLVIIIB isolate. Whether LAV and IIIB are distinct isolates remains a matter of contention, but the sequences of the two isolates are highly related. There are small differences in the envelope sequences of these two isolates, as there are between different molecular clones derived from the IIIB isolate. For the sake of consistency, we will refer to these strains as IIIB.

Laboratory workers. The first laboratory worker (LWF) has been described elsewhere (10). The event causing exposure to HIV has not been defined and occurred prior to 1986 . LWF is currently healthy with a CD4 cell count $<500 / \mathrm{mm}^{3}$. The second laboratory worker (LWS) became infected in 1990 following exposure of the skin and mucous membranes to concentrated $\mathrm{HIV}_{\text {IIIB }}$. LWS is currently healthy, but has received anti-HIV therapy for CD4 cell count $<300$. The anonymity of the laboratory workers has been carefully guarded. 
Serial clinical, viral, and immune studies have been performed, and details will be published elsewhere (W. A. Blattner, et al., manuscript in preparation). We show samples representing both early (LWS) and late (LWF) postexposure time points.

Vaccination protocols. Vaccination protocols were defined and managed by the National Institute of Allergy and Infectious Diseases AIDS Vaccine Clinical Trials Network. All vaccinees were seronegative, healthy volunteers. The first group of vaccinees (amended protocol 002 , designated with the letter A) received one or two immunizations of $10^{7}-10^{9} \mathrm{pfu} / \mathrm{ml}$ vaccinia virus expressing gp $160_{\text {IIIB }}$ by bifurcated needle puncture (HIVAC-1e; Bristol Myers Squibb/Oncogen, Seattle, WA) $(1,12)$ followed 2-18 mo later with a booster immunization of $640 \mu \mathrm{g}$ of alum adsorbed rgp $160_{\text {IIIв }}$ (VaxSyn HIV-1; MicroGeneSys, Meriden, CT) (13). The other group of vaccinees (protocols $003 \mathrm{~A}$ and $003 \mathrm{~B}$, for convenience both are referred to as 003 ) received three or four immunizations with the alum adsorbed rgp 160, at a dose of either $160 \mu \mathrm{g}$ (vaccinees designated with the letter $\mathrm{E}$ ) or $640 \mu \mathrm{g}$ (F vaccinees) (2). Sera used in this study were selected as representing the highest titers of anti-gp160 antibody produced in vaccinees from these protocols.

Monoclonal antibodies. The following anti-gp $160 \mathrm{mAbs}$ have been described elsewhere: 924, directed against the V3-loop $(14,15)$; 41.1, recognizing the immunodominant region of $g p 41(15,16)$, and F105, which blocks the conformationally dependent $\mathrm{CD} 4$ binding site of gp1 20 (17). mAbs B8 and C8 were derived from separate BALB/cJ mice immunized with $10 \mu \mathrm{g}$ of rgpl60 (MicroGeneSys) in complete Freund's adjuvant. Booster immunization of $1-5 \mu \mathrm{g}$ rgp 160 in saline was given daily for $4 \mathrm{~d}$ before killing of mice and fusion of splenocytes to SP2/0 cells.

Immunoassays. ELISA were performed using recombinant and peptide antigens as described elsewhere (15). Baculovirus preparations of gp $160_{\text {IIIB }}$ were obtained from Repligen (Cambridge, MA) and MicroGeneSys. The Repligen product was actively denatured. Synthetic peptides were obtained from American Bio-Technologies (Cambridge, MA) or synthesized at the Rocky Mountain Laboratories on a peptide synthesizer (model 431A; Applied Biosystems Inc. Foster City, CA). Binding of antibody to the antigen was detected with alkaline phosphatase-conjugated secondary antibodies: goat anti-human immunoglobulins; heavy chain specific goat anti-human mu, gamma, or alpha chain; murine monoclonal anti-human IgG1, IgG2, IgG3, or IgG4; or goat anti-mouse immunoglobulins (all from Zymed Laboratories, South San Francisco, CA).

Epitope scanning was performed according to the method of Geysen (18). A set of 283 overlapping 12-mer peptides was constructed on solid supports using materials and protocols supplied by Cambridge Research Biochemicals (Wilmington, DE). Peptides started every third AA (starting at the amino terminus) and thus had a nine AA overlap. The peptides were bound to the solid matrix on the pins via a linker at the carboxy terminus of the peptide. Sequences used to construct the peptides and the numbering of the AAs in this publication conform respectively to those of the BH10 and HXB-2 molecular clones of HTLV-IIIB (19). Two control pins with an irrelevant peptide and one with no peptide were included. The solid supports were arranged so that the tip of each support, which contains the peptide, fits in a well of a 96-well microtiter plate. Prior to use the peptides were blocked with 3\% BSA (Sigma Chemical Co., St. Louis, MO), 0.1\% Tween-20 in PBS. The supports were then incubated in the presence of the test serum diluted 1:1000 in PBS containing 1\% BSA overnight at room temperature. The supports were then washed four times and incubated with alkaline phosphatase-conjugated goat anti-human immunoglobulins for $2 \mathrm{~h}$ and washed again. Substrate ( $P$-nitrophenyl phosphate $0.5 \mathrm{mg} / \mathrm{ml}$, Sigma) was added, and $\mathrm{A}_{405}$ was determined 90-120 min later. Data are reported with the background absorbance of the control pins subtracted. Following each use the antibody was desorbed from the pins by sonication for $30 \mathrm{~min}$ and then boiling in methanol for $20 \mathrm{~min}$. The efficacy of the desorption was tested by adding the alkaline phosphatase-conjugated secondary antibody and then the substrate. No residual antibody was found following any desorption.

Viral neutralization was performed using a focal infectivity assay (FIA ) $(14,20)$. The molecularly cloned HIV strain NL4-3 was used in the neutralization assays. A pretitered dilution of cell-free virus was mixed with the serum to be tested and incubated for $1 \mathrm{~h}$ at $37^{\circ} \mathrm{C}$. The mixture was then transferred to a monolayer of CD4+ HeLa cells (cell line 1022). The mixture was incubated on the monolayer for $3 \mathrm{~h}$ at $37^{\circ} \mathrm{C}$. The monolayer was then washed and the cells incubated for $3 \mathrm{~d}$. The cells were fixed with ethanol and stained with a human anti-HIV serum, peroxidase-conjugated anti-human immunoglobulins, and substrate (amino ethyl carbazole; Sigma). Viral foci were identified as multinucleated cells staining with the peroxidase substrate.

Inhibition of the interaction between soluble CD4 (sCD4) and gp120 was measured by ELISA. gp 120 ${ }_{\text {IIIB }}$ (American Bio-Technologies) was adsorbed to microtiter plates at $3 \mu \mathrm{g} / \mathrm{ml}$. After this, microtiter plates were blocked with PBS/BSA. Then the serum to be tested was added and incubated $1 \mathrm{~h}$ at $37^{\circ} \mathrm{C}$. Following this sCD4-biotin was added to the serum in the microtiter well. sCD4 (American Bio-Technologies) was biotinylated using an $\mathrm{N}$-hydroxy-succinimide ester of biotin (Binding Site, Inc., San Diego, CA ), and an appropriate dilution was determined by titration in the absence of sera. After an overnight incubation, the plates were washed and the binding of SCD4 to the microtiter plates was measured with alkaline phosphatase-conjugated avidin (Binding Site, Inc.) and $p$-nitro phenyl phosphate. The specificity of this assay was demonstrated with mAbs that are known either to block this interaction or to bind to other portions of $\mathrm{gp} 120$.

Flow cytometry was performed on $\mathrm{H} 9$ cells persistently infected with NL4-3 (15). Cells were incubated with $\mathrm{mAbs}$ at $10 \mu \mathrm{g} / \mathrm{ml}$ in PBS/BSA with $0.1 \%$ azide for $1 \mathrm{~h}$ at room temperature, washed, and incubated with fluorescein conjugated goat anti-mouse immunoglobulins (Organon-Teknika, Malvern, PA). After $1 \mathrm{~h}$, the cells were washed, fixed in $2 \%$ paraformaldehyde, and analyzed with single-colorflow cytometry on a Becton Dickinson FACSTAR ${ }^{\circledR}$ (Mountain View, CA). Immunotoxins were prepared by conjugating mAbs to ricin $A$ chain and cytotoxicity of the immunotoxins on H9/NL4-3 cells measured as described elsewhere (15). Cells were incubated with the immunotoxin for $72 \mathrm{~h}$ and pulsed with $\left[{ }^{35} \mathrm{~S}\right]$ methionine for the final $16 \mathrm{~h}$.

\section{Results}

Antibody titers and isotypes. We have measured the amount of anti-gp160 using an ELISA with recombinant baculoviral gp 160. Table I shows antibody binding in laboratory workers, vaccinees ( 2 wk following booster immunization), and normals. Laboratory worker sera, from the earliest time point (several months postinfection), have high levels of anti-gp160, as does HIVIG, a pool of immune globulin obtained from multiple HIV-seropositive individuals (21). Comparable amounts of gp160-binding antibody were seen in the majority of this selected group of vaccinees. There was no consistent difference between the two immunization protocols. Three 002 vaccinees produced no anti-gp160 detectable at this serum dilution, while several of the vaccinees produced antibody levels as high or higher than the lab workers. However, serum antibody titers began to fall in the vaccinees within the next month (not shown). All experiments shown below use the $2 \mathrm{wk}$ post-boost vaccinee samples.

The V3 loop amino acid (AA) ${ }^{1} 296-331$ is a hypervariable, immunodominant region of $\mathrm{gp} 120$ that serves as a principal target for neutralizing antibody, and plays an important role in HIV cell-tropism (22-24). Antibodies to this region were measured using a synthetic peptide that corresponds to AAs 297-

1. Abbreviation used in this paper: AA, amino acid. 
Table I. Binding of Sera to rgp160 and V3-Loop Peptide

\begin{tabular}{|c|c|c|c|c|}
\hline \multirow[b]{2}{*}{ Serum* } & \multicolumn{2}{|c|}{ Binding to $\mathrm{rgp} 160^{\ddagger}$} & \multicolumn{2}{|c|}{$\begin{array}{c}\text { Binding to V3 loop } \\
\text { peptide }^{5}\end{array}$} \\
\hline & Mean & SEM & Mean & SEM \\
\hline E3 & 1.196 & 0.126 & 0.173 & 0.004 \\
\hline E5 & 1.247 & 0.062 & 0.177 & 0.008 \\
\hline E6 & 1.345 & 0.042 & 0.173 & 0.004 \\
\hline F11 & 1.475 & 0.014 & 0.383 & 0.037 \\
\hline F13 & 1.677 & 0.047 & 0.162 & 0.007 \\
\hline F14 & 2.407 & 0.084 & 0.226 & 0.009 \\
\hline A 24 & 0.330 & 0.030 & 0.143 & 0.015 \\
\hline A28 & 1.316 & 0.063 & 1.722 & 0.055 \\
\hline A20 & 1.612 & 0.073 & 1.720 & 0.087 \\
\hline A 12 & 0.434 & 0.059 & 0.294 & 0.005 \\
\hline A17 & 2.065 & 0.200 & 2.053 & 0.058 \\
\hline A22 & 2.075 & 0.138 & 1.881 & 0.100 \\
\hline A29 & 0.178 & 0.001 & 0.232 & 0.012 \\
\hline A42 & 1.367 & 0.054 & 0.331 & 0.049 \\
\hline LWS 9/90 & 2.102 & 0.094 & 2.306 & 0.072 \\
\hline LWS $10 / 90$ & 1.912 & 0.038 & 2.388 & 0.168 \\
\hline LWS 4/91 & 2.168 & 0.223 & 2.488 & 0.150 \\
\hline LWS 8/91 & 2.325 & 0.190 & 2.425 & 0.099 \\
\hline LWF 9/90 & 2.041 & 0.123 & 1.438 & 0.101 \\
\hline NHS A & 0.261 & 0.014 & 0.267 & 0.030 \\
\hline NHS E & 0.487 & 0.033 & 0.186 & 0.012 \\
\hline HIVIG & 1.697 & 0.069 & 0.333 & 0.016 \\
\hline
\end{tabular}

* Serum samples diluted 1:1000. Samples designated $E$ and $F$ are from protocol 003 , A samples are from the amended 002 protocol, LW are lab workers, and NHS are normal sera. ${ }^{\ddagger} \mathrm{A}_{405}$ obtained in ELISA with wells coated with baculovirus rgp 160 and detected with goat anti-human Ig conjugated to alkaline phosphatase. Mean and SEM of triplicate samples. ${ }^{\S}$ Binding to wells coated with V3 loop peptide TRPNNNTRKSIRIQRGPGRAFVTIGKIGNMRQAH.

330 (Table I). Laboratory workers produced high levels of anti-V3 antibody. Four vaccinees from protocol 002 (A28, $\mathrm{A} 17, \mathrm{~A} 20$, and $\mathrm{A} 22$ ) produced anti-V3 in amounts comparable to those seen in the laboratory workers. None of the 003 vaccinees produced measurable anti-V3, even though they had equivalent titers of anti-gp 160 as the laboratory workers.

The class and IgG subclass of the anti-gp160 response were measured by ELISA (Fig. 1). The predominant response in both the vaccinees and the laboratory workers was $\mathrm{IgG}$, with $\mathrm{IgG} 1$ and $\mathrm{IgG} 3$ subclasses predominating. One vaccinee (A17) produced a significant level of serum IgA. The anti-V3 response (only typable in the lab workers) was also of the IgG1 and IgG3 isotype. Although only the 002 vaccinees are shown in Fig. 1, similar isotypes were produced by the 003 vaccinees.

Functional measurement of antibody. We have used a focal infectivity assay to measure the neutralization of cell-free HIV by human sera (Fig. 2). Since the serum was only present for 3 $h$ during the time of infection of the monolayer cells with cellfree virus, this assay measures only antibody-mediated inhibition of HIV attachment and initial infectious events. Normal sera showed no inhibition of focus formation. Laboratory workers produced high titers of neutralizing antibody, with complete inhibition seen at dilutions as great as 1:500 at some time points. In this assay only two vaccinees (A28 and A22) clearly produced even low titers of neutralizing antibody. A third serum (A17) gave marginal neutralization. Although only five vaccinees from protocol 002 are shown in the figure, we have tested nine 002 and six 003 vaccinees and found that no others had any detectable neutralizing antibody. The neutralization results we have obtained with the 002 vaccinees are comparable with those reported using a different technique by the Central Immunology Laboratory of the NIAID AIDS Vaccine Clinical Trials Network although our actual titers are somewhat lower (13).

Another way in which antibody may protect against HIV is by inhibiting the interaction between gp120 and its cellular receptor CD4. Recently, both monoclonal and polyclonal antibodies with CD4-gp 120 inhibiting activity have been described and their functional activity demonstrated $(17,25)$. Such antibodies appear to recognize conformational epitopes on $\mathrm{gp} 120$. We have measured these by ELISA, in which the binding of biotinylated CD4 to immobilized gp120 is inhibited with the
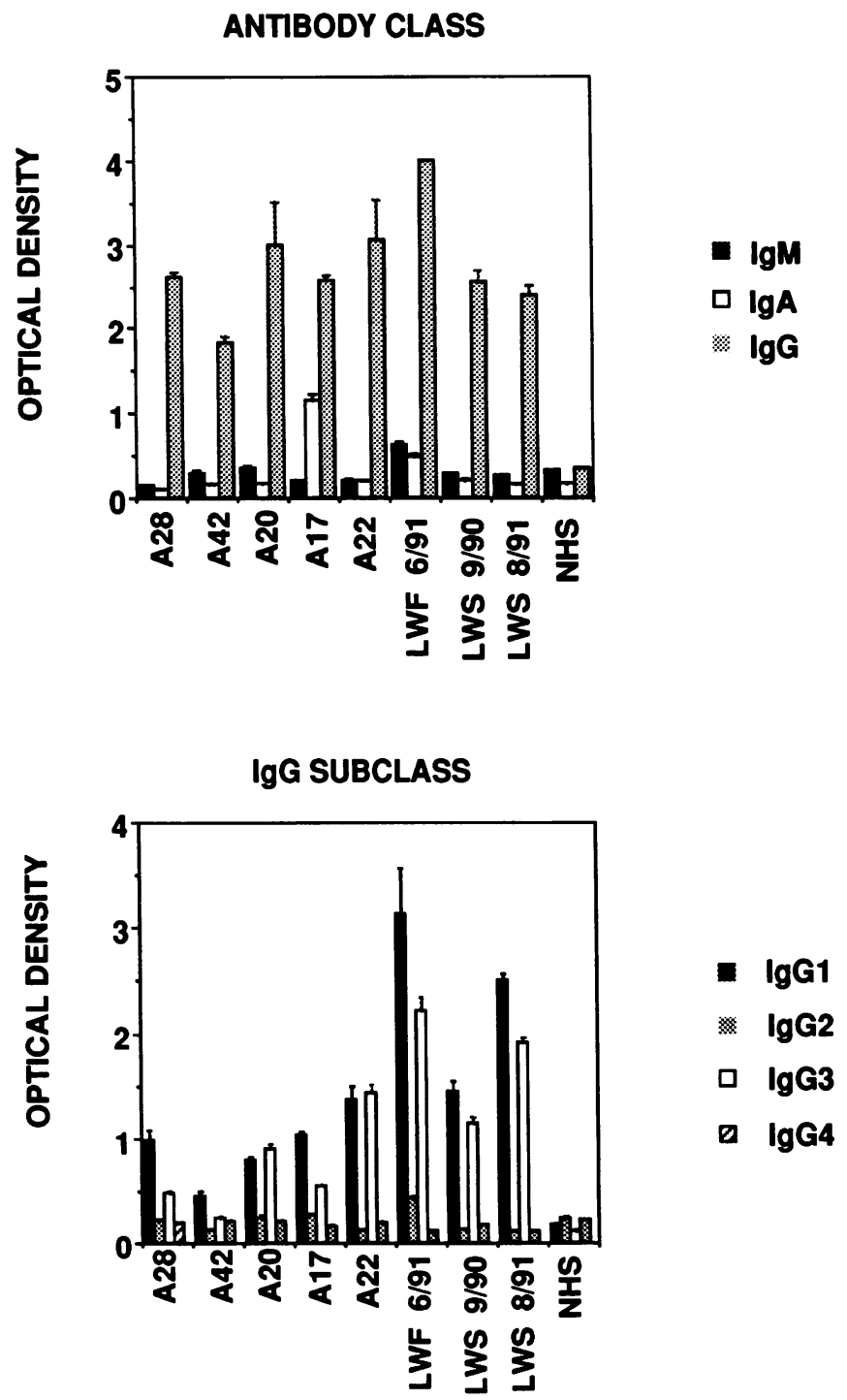

Figure 1. Isotype of anti-gp160 antibody. ELISA was performed on rgp 160. Antibody isotype was determined with class-specific (top) or IgG subclass-specific (bottom) alkaline phosphatase-conjugated antibodies. Data points are means and standard errors of triplicate samples. 


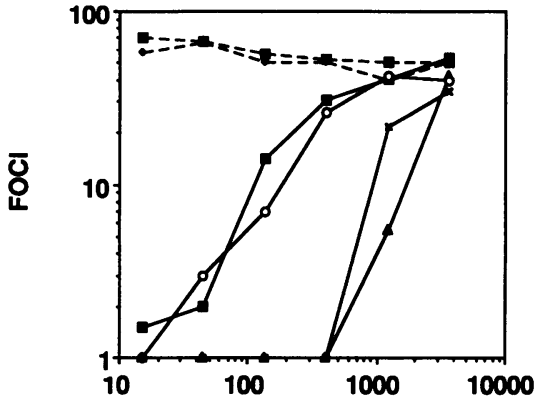

LAB WORKERS and CONTROLS
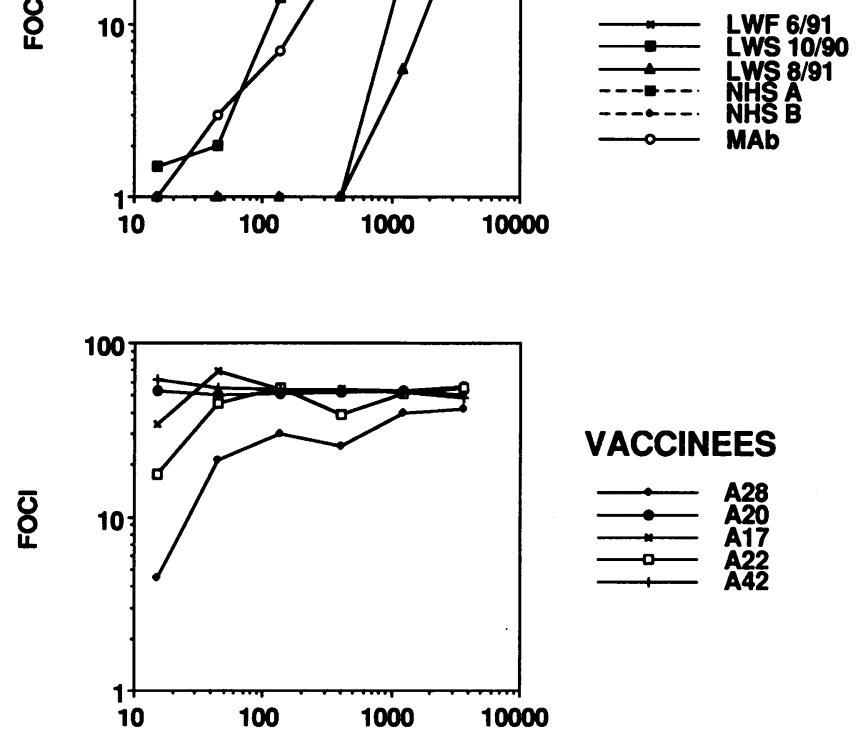

\section{RECIPROCAL DILUTION}

Figure 2. Neutralization of HIV infection by antisera. Antibody mediated neutralization of infection of the CD4+ HeLa cell line 1022 was measured by FIA. The top figure shows lab workers, normals, and anti-V3 mAb 924 (highest concentration $10 \mu \mathrm{g} / \mathrm{ml}$, then following the same serial dilutions). The bottom displays data of vaccinees from the 002 protocol. Data represent the number of foci counted per microtiter well.

test sera (Fig. 3). Positive controls, including sCD4 and mAb F105, inhibited this binding (Fig. 3, top), while antibodies directed against linear epitopes on gp 120, including the V3 loop, did not inhibit (not shown). Measurable titers of CD4-gp120 inhibiting antibody were detected in both laboratory workers and HIVIG. Three vaccinees from protocol 002 (A28, A22, and A17) developed inhibiting antibody. The titer was somewhat lower in these vaccinees than in the laboratory workers. No 003 vaccinees produced detectable inhibiting antibodies.

Epitope mapping analyses. We have constructed a set of 283 overlapping 12-mer peptides that represent the entire sequence of gp $160_{\text {IIIB }}$. The peptides were immobilized on pins according to the method of Geysen (18). The first peptide includes AA 1-12. Each successive peptide was started three AA toward the carboxy terminus (e.g., peptide 2 encompasses AA 4-15), producing a nine-AA overlap. Initial analyses with these pins included mapping mAbs of known epitope specificity and titrations of lab worker and normal sera. Appropriate reactivities were detected with mAbs. It was determined that the best signal-to-noise ratio was obtained using serum at a 1:1000 dilution. The qualitative nature of the Geysen analyses must be emphasized. Only a single serum was tested at a time. Quantitative comparisons among sera cannot be made.

We tested seven serial samples on LWF, four on LWS. All vaccinees listed in Table I were tested, as were five sera from unimmunized seronegative individuals. There were several regions that were consistently positive in either vaccinees, laboratory workers, or both. These include the V3 loop (both), the gp41 immunodominant region, AA 575-604 (26) (both), the putative CD4 binding site AA 420-445 (27) (laboratory workers only), and a mid-gp41 region AA 720-740 (28) (vaccinees only). Detailed analyses of the V3 and the mid-gp41 regions are shown below.

Fig. 4 shows the fine specificity of the antibody response to V3 peptides. In all 11 samples from the laboratory workers (three of which are shown), peptide 8 was highly immunodominant. This peptide is located at the "tip" of the V3 loop and contains the conserved core sequence GPGRAF. Neutralizing mAb 924 bound to peptide 10. Antibody from vaccinees in protocol 003 predominantly reacted with peptides 5-8 (as exemplified by vaccinee $E 5$, shown in the figure). In all vaccinees from protocol 002 , peptide 11 was a site of reactivity, but there was also binding to other peptides in the $\mathrm{V} 3$ region in a variable pattern. We have tested for antibodies that cross-react with peptides corresponding to the V3 loops (AA 302-322) of 10 heterologous HIV strains. Lab worker sera reacted with peptides corresponding to the $\mathrm{MN}$ and $\mathrm{RF}$ isolates.

Vaccinees made a major antibody response to the midgp41 region that did not occur in laboratory workers. This is shown in Fig. 5. A shows the binding to the specific peptides in this region. B, which shows the results of binding to all 283 gp160 peptides, is shown to demonstrate the dominance of this mid-gp4l antibody response in vaccinees. This is the major antibody peak in all 002 vaccinees, as detected by epitope scanning analyses. Vaccinees in protocol 003 had a more variable response, with only three of six showing reactivity in this region. We have confirmed these data by constructing a soluble peptide corresponding to AA 718-741 and quantitatively comparing the antibody response in all vaccinees and the labora-
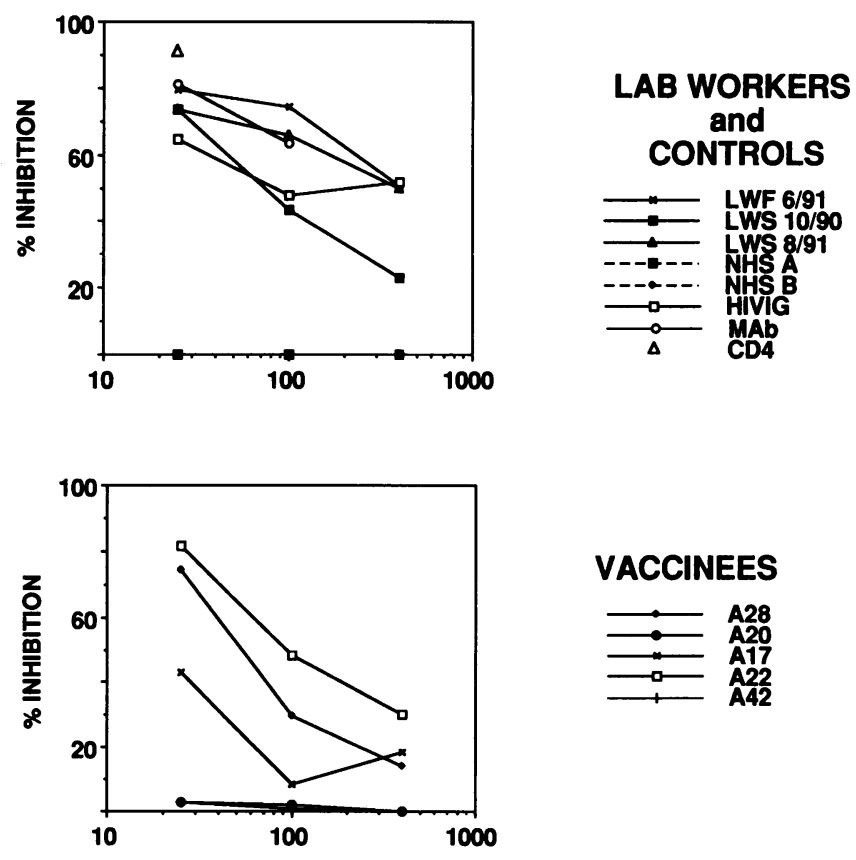

VACCINEES

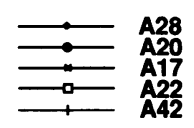

RECIPROCAL DILUTION

Figure 3. Inhibition of CD4-gp 120 binding. The ability of sera to inhibit the interaction between $\mathrm{gp} 120$ and CD4 was measured by ELISA. Controls include CD4 ( $10 \mu \mathrm{g} / \mathrm{ml})$ and $\mathrm{mAb}$ F105 ( 10 and 2 $\mu \mathrm{g} / \mathrm{ml}$ ). The data are calculated as percent inhibition by comparison to the binding of CD4 to gp120 seen in the absence of any inhibitor. 

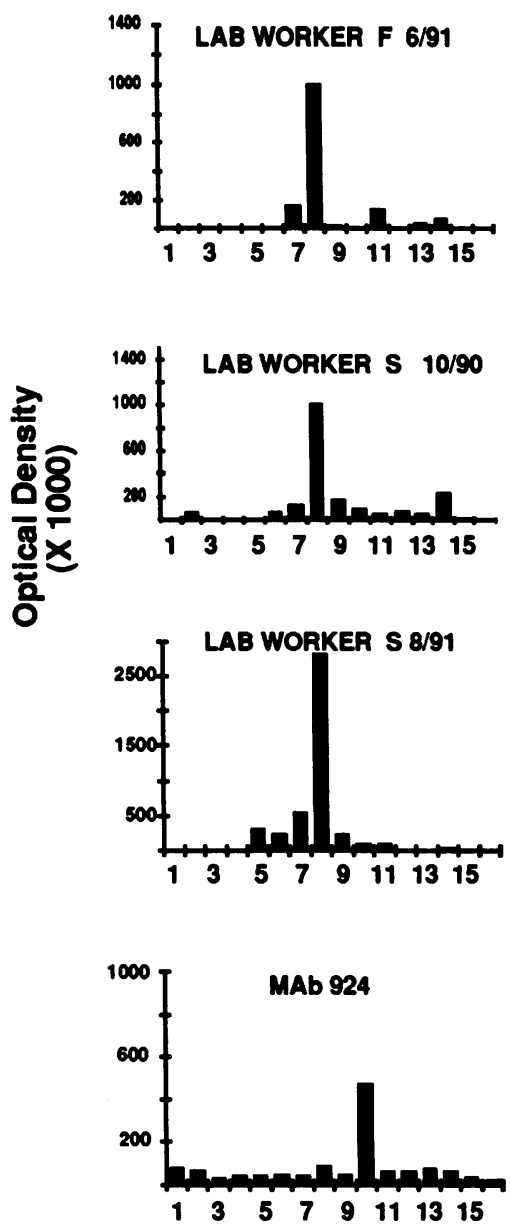
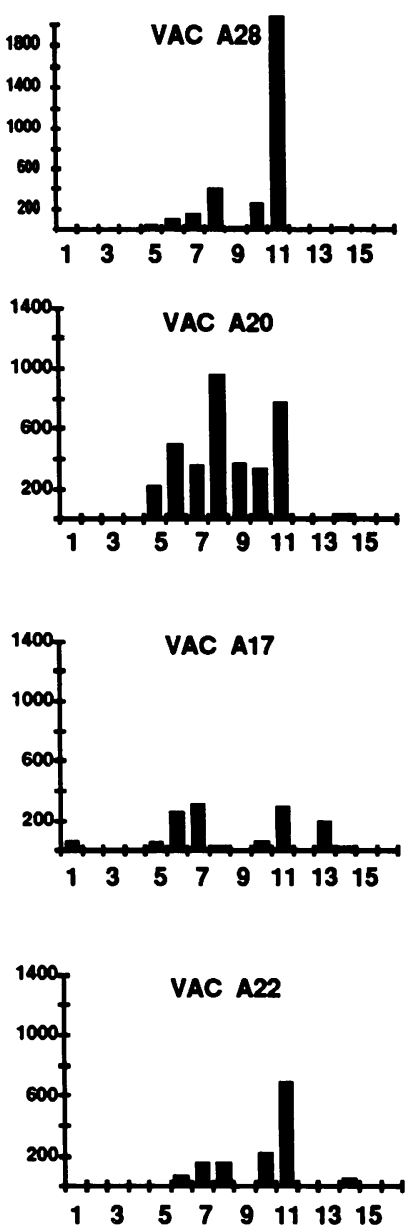
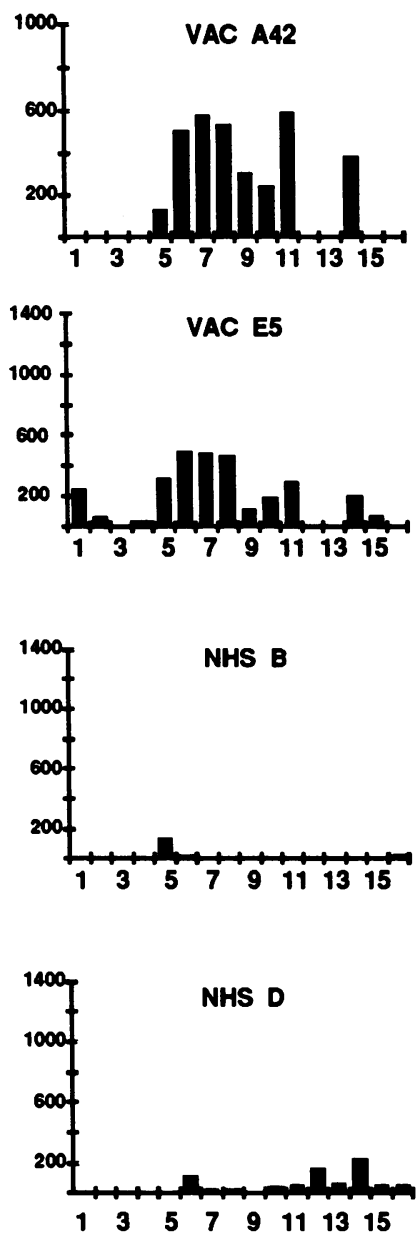

\section{Peptide Number}

Figure 4. Geysen peptide analysis of the fine specificity of anti-V3 response. Epitope scanning was performed individually on each lab worker, vaccinee, or normal serum. Sera were tested at 1:1000 dilution on a set of immobilized Geysen peptides. Binding was detected with anti-human Ig conjugated to alkaline phosphatase followed by chromogenic substrate. Although all sera were tested against 283 overlapping 12 -mer peptides, only the results with peptides corresponding to the V3 region are shown above. The peptides are arrayed on the $x$ axis of the figure with that closest to the amino terminus on the left (No. 1) and proceeding toward the carboxy-terminal peptides to the right. The peptides were: 1 . VQLNQSVEINCT, 2. NQSVEINCTRPN, 3. VEINCTRPNNNT, 4. NCTRPNNNTRKS, 5. RPNNNTRKSIRI, 6. NNTRKSIRIQRG, 7. RKSIRIQRGPGR, 8. IRIQRGPGRAFV, 9. QRGPGRAFVTIG, 10. PGRAFVTIGKIG, 11. AFVTIGKIGNMR, 12. TIGKIGNMRQAH, 13. KIGNMRQAHCNI, 14. NMRQAHCNISRA, 15. QAHCNISRAKWN, 16. CNISRAKWNNTL.

tory workers. There was no correlation between the production of antibody to this epitope and neutralization.

To study the function of antibodies to this region, we have analyzed two murine $\mathrm{mAbs}$ that react with mid gp41 peptides: C8 reacts with peptides 5, 6, and 7 (as numbered in Fig. 5), while B8 reacts with 8 and 9 . Fig. 6 shows the results of three different analyses with $\mathrm{C} 8$ and B8 antibodies. Expression of viral antigens on the surface of HIV-infected cells was examined by flow cytometry $(A)$. The V3 loop (detected with mAb 924 ) was well expressed, while neither C8 nor B8 bound to the cell surface. Antibody-mediated neutralization of cell-free virus by $\mathrm{mAbs}$ is shown in $B$. While 924 gives $50 \%$ inhibition at $3 \mu \mathrm{g} / \mathrm{ml}$, no inhibition was seen at any concentration with either C8, B8, or a mixture of both. As an extremely sensitive test of the ability of antibody C8 to function in the removal of HIV-infected cells, we coupled the antibody to ricin A-chain and tested whether it functioned as an immunotoxin (15). C compares the $\mathrm{C} 8$ immunotoxin with another anti-gp41 mAb (41.1) coupled to ricin A chain. Antibody 41.1 recognized a surface-exposed epitope near the amino terminus of gp41 and was highly effective in killing infected cells at concentrations as low as $0.3 \mu \mathrm{g} / \mathrm{ml}$; there was no significant difference between $\mathrm{C} 8$ and the irrelevant control antibody $\mathrm{T} 7$ at any dose. There was marginal suppression by $\mathrm{C} 8$ immunotoxin at the highest concentration $(10 \mu \mathrm{g} / \mathrm{ml})$. This was a reproducible phenomenon, but it always occurred in the dose range where the irrelevant antibody gave nonspecific suppression. The experiments shown in Fig. 6 were performed with one strain of HIV. The C8 immunotoxin was also tested on $\mathrm{MN}$ and SF2 isolates and found ineffective. The data obtained with mAbs C8 and B8 suggest that antibody to the mid-gp4l epitope is not likely to have a functional effect. These data contradict those of other studies of this epitope, which suggest that this is a weak, but cross-reactive, neutralizing epitope (28-32). 

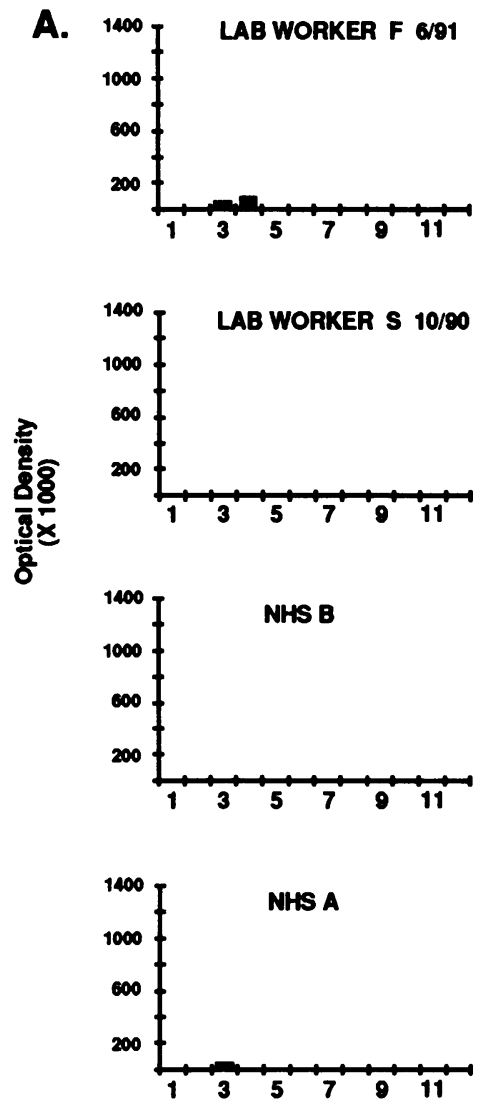
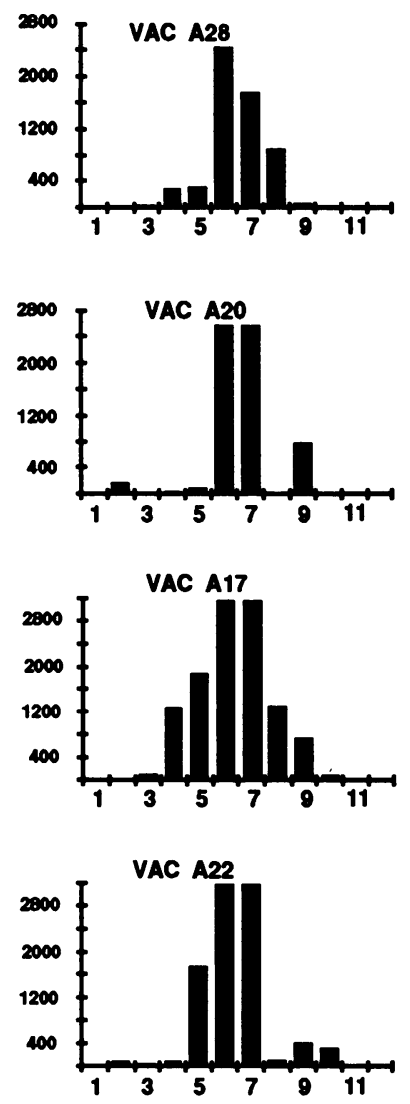
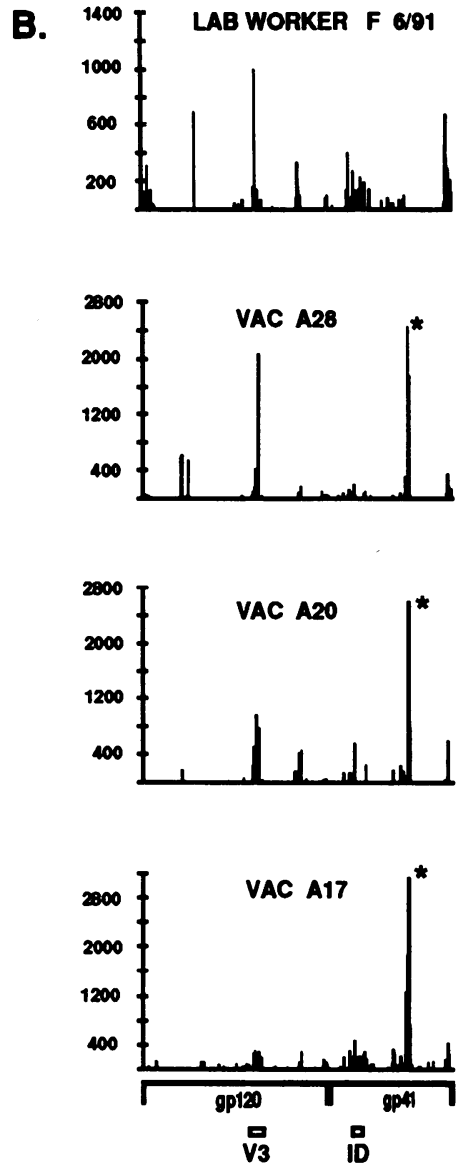

\section{Peptide Number}

Figure 5. Peptide analysis of the antibody response to mid-gp41 epitope. A major area of immunoreactivity was found in the 002 vaccinees in the region of AAs 720-740. The results of epitope scanning on Geysen peptides on selected sera are shown above. $A$ shows the results for only this region, while $B$ shows the results for the entire set of gp160 peptides. The peptides in $A$ are: 1. RQGYSPLSFQTH, 2 . YSPLSFQTHLPI, 3. LSFQTHLPIPRG, 4. QTHLPIPRGPDR, 5. LPIPRGPDRPEG, 6. PRGPDRPEGIEE, 7. PDRPEGIEEEGG, 8. PEGIEEEGGERD, 9. IEEEGGERDRDR, 10. EGGERDRDRSIR, 11. ERDRDRSIRLVN, 12. RDRSIRLVNGSL. The 283 peptides represented in $B$ are arrayed with the amino-terminal peptides on the left and proceeding toward the carboxy terminus on the right. The schematic diagram at the bottom of $B$ indicates the location of the peptides with gp 120, gp41, V3 loop, and the gp41 immunodominant regions (ID) marked. The mid-gp41 peak in the vaccinees is indicated with an asterisk.

\section{Discussion}

The definition of what constitutes protective immunity for HIV infection is not yet established. Important issues remain unsettled. For example, the relative roles played by humoral and cellular immune responses in protection have not been defined. Important open questions regarding humoral immunity include whether in vitro neutralization is a reliable surrogate for in vivo protection, whether or not there are antibodies that can enhance infection in vivo (33), and whether a systemic immune response will be adequate to protect against infection that most frequently is initiated at mucosal surfaces. Studies with chimpanzees involving both active and passive immunization have shown that protection against intravenous challenge with HIV is most closely associated with the presence and titer of neutralizing antibody (4-8). But whether these results can be applied to human populations is problematic. There is no direct way of answering these questions short of a large scale efficacy trial. However, carefully performed in vitro analyses may be useful in predicting the candidate vaccines with greatest potential.

In this paper, we compared systemic antibody responses following immunization and natural infection. We minimized effects due to HIV variation by using sera from laboratory workers infected with the same strain of HIV (HTLV-IIIB/ LAV) used to prepare the vaccine. The laboratory worker sera were compared with selected high titer vaccinee sera. The analyses indicate that current immunization protocols can induce antibodies to important epitopes, but there were significant differences in the quality and fine specificity of the antibody response in vaccination and natural infection.

Natural infection should be an excellent route for the induction of immunity for several reasons (9). It results in prolonged exposure to a replicating antigen. Infection results in exposure to an immunizing antigen that is identical to the target antigen; all current HIV vaccines differ in some way from 


\section{A. CELL SURFACE BINDING BY FLOW CYTOMETRY}

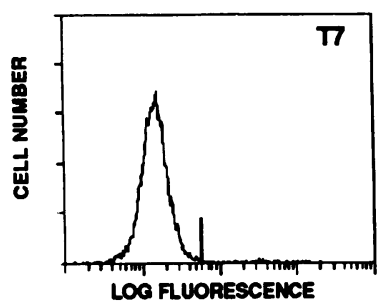

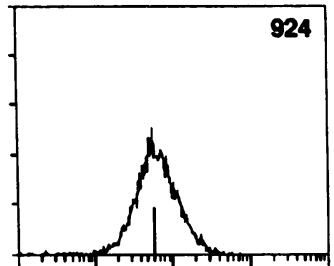

LOQ FLUORESCENCE

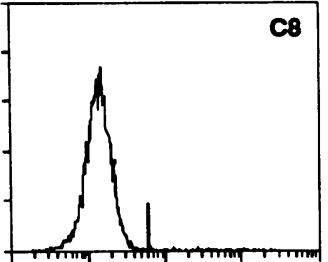

LOQ FLUORESCENCE

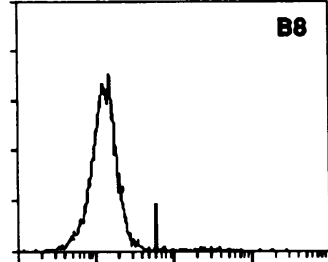

LOQ FLUORESCENCE
B. NEUTRALIZATION

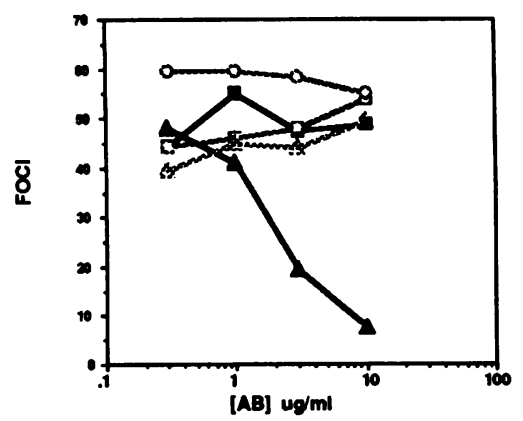

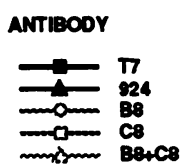

Figure 6. Functional activity of mAbs corresponding to mid-gp41 region. Mabs were tested for binding to HIV infected cells by flow cytometry $(A)$. The short vertical lines are placed in the same location in each figure to ease comparisons. Neutralization of HIV infectivity as measured by focal infectivity assay (FIA) is shown in $B$. Function of the mAbs as an immunotoxin after coupling to ricin $A$ chain was also tested $(C)$. Immunotoxin function was measured as the suppression of protein synthesis in HIV-infected cells $\left(\left[{ }^{35} \mathrm{~S}\right]\right.$ methionine incorporation $)$. mAbs used were: $\mathrm{T} 7$ an irrelevant control mAb, 924 directed against the $\mathrm{V} 3$ loop, 41.1 which binds the gp41 immunodominant region, C8 and B8 which recognize epitopes within the mid-gp41 region. All assays were performed using the molecularly cloned HIV NL4-3.

the true virus. While it is clear that natural infection does not result in immunity that completely protects against disease progression once infection has occurred, evidence supports the idea that natural infection does protect against a later reinfection with HIV. For example, there have been no documented cases where two distinctly different HIV-1 isolates have been obtained from a single individual, although the technology exists to identify such isolates by signature sequences. Thus, comparison to the immunity arising in natural infection is likely to be useful in identifying parameters that may define immunity that protects against infection with HIV.

Although several vaccinee sera contained anti-gp160 antibodies of similar titer and isotype to those of lab worker sera, there were significant differences in the specificity and functional activities of the antibody produced. Lab worker sera neutralized in high titer; sera from vaccinees did not. The epitope specificity of the antibody was also different. Anti-V3 bound to different portions of the loop. The vaccinees produced a large response to an epitope in mid-gp41 (AA 720-740), while the lab workers did not. Our studies with mAbs suggest that this latter epitope may be functionally irrelevant (Fig. 6).

Interestingly, we also found that immunization protocol influenced the quality of the antibody. Both protocols used recombinant gp 160. However, in protocol 002 primary immunization was with recombinant gp 160-vaccinia virus vaccine (HIVAC-1e) $(1,12)$, while in protocol 003 subjects received alum precipitated purified rgpl60 (VaxSyn HIV-1) as the primary immunization (2). Vaccinees in both protocols were boosted with purified gp160. In our assays, the only subjects who produced significant amounts of anti-V3, neutralizing, or CD4-gp 120 inhibiting antibodies were from the 002 protocol. The 002 protocol also resulted in most antibody directed against the mid-gp41 epitope, both in terms of the magnitude of the response and the proportion of vaccinees producing the antibody. There may also have been a difference in the fine specificity of the anti-V3 response in the two protocols, but these studies were hampered by the low titers of anti-V 3 in the 003 vaccinees.

The use of synthetic peptides to map the epitope specificity of the antibody response must be approached with caution ( 18 , $34)$. The proportion of antibodies that react with linear epitopes (which can be mapped with peptides) as opposed to three-dimensional conformational epitopes (requiring native protein) is not known. Our experience in mapping mAbs suggests that approximately two-thirds of murine and human anti-gp160 mAbs can be mapped with synthetic peptides ( 15 , and S. H. Pincus, K. G. Messer, and G. Fisher, unpublished observations). But, this cannot be extrapolated to polyclonal sera, nor does it indicate that antibodies that bind peptides might not bind the same epitope better in its native conformation. Furthermore the effects of glycosylation patterns, which differ among the vaccine preparations and can influence immu- 
nogenicity, may not be reflected in analyses using synthetic peptide antigens. Given these caveats, our analyses with the immobilized "Geysen" peptides offer encouragement to those who wish to use this technique to map human antibody responses. In contrast to a recent report (34), we have seen reproducible differences in binding between nonimmune and immune sera, as well as consistency within experimental groups. We have confirmed results obtained on the Geysen pins with soluble peptides. We attribute our success with this technique to our initial titrations of both immune and nonimmune sera on the peptides, as well as careful attention to blocking of pins and removal of bound antibody between analyses. Epitope scanning techniques allow analysis of the polyclonal antibody response in unprecedented detail.

The nature of neutralizing antibody is important to determine. At least two important components have been defined: anti-V3 and CD4-gp120 inhibiting antibodies. Monoclonal and polyclonal antibodies to the V3 loop neutralize well (14, $22,23,35,36)$ and can prevent experimental infection (8). Because V3 synthetic peptides can induce neutralizing antibody, it is thought that the V3 neutralizing determinant may be a linear epitope. In contrast, CD4-gp120 inhibiting antibody may be conformational $(17,25)$, although several inhibiting mAbs have been mapped to a specific epitope (AA 420-445) $(27,37)$. Neutralizing antibodies have been reported against other specific regions of gp120 $(38,39)$, but these may represent CD4-gp120 inhibiting antibodies. Neutralization has also been reported with anti-gp41, in particular with antibodies to the mid-gp41 epitope AA 720-740 (28-31) and to a conserved epitope at AA 672-677 (40). The mechanism whereby antigp4 1 antibodies might neutralize is not known. We have used an FIA to measure neutralization of HIV infection by antibody $(14,20)$. Because the antibody was present only during the incubation of the target cells with cell free virus, this assay measured only early neutralization events, and not such later events as inhibition of syncytia formation or secretion of virus by infected cells. Thus our assay may only have measured a subset of neutralizing antibodies. In our studies, we found that fine specificity of anti-V3 correlated best with the production of neutralizing antibody. Infection resulted in antibody that reacted with a peptide corresponding to the "tip" of the V3 loop and high titers of neutralizing antibody, while sera from some 002 vaccinees who had equal titers of antibody to the whole loop, but bound to other peptides, neutralized only weakly. However, one 002 vaccinee (A20) produced high titer anti-V3 with antibody binding the peptide corresponding to the "tip" and yet had no neutralizing antibody. The three vaccinees who produced neutralizing antibody (A28, A17, and A22) were also the only vaccinees who produced CD4-gp120 inhibiting antibody. There was no evidence to suggest any correlation between neutralization and antibody to the midgp4l epitope. It is likely that the neutralizing antibody response results from the additive effect of antibodies to several different specificities.

In light of the impressive response of the 002 vaccinees to the mid-gp41 epitope, it is extremely important to determine the antiviral capacity of antibody to this epitope. Our data with mAbs C8 and B8 indicate that antibody to this epitope is unlikely to inhibit HIV. These analyses were performed with three different strains of HIV and with both cell-free and cellassociated HIV. Our mAb analyses are also consistent with the low degree or absence of neutralization seen in vaccinee sera with high titers of antibody to the mid-gp41 epitope. Most structural predictions suggest this epitope lies on the cytoplasmic side of the cell membrane (26). Yet there are persistent reports that this epitope has functional significance (28-32). At the very best, only weak neutralizing responses were obtained following immunization with peptide corresponding to this epitope. It is possible that differences in HIV isolates, cell lines, stringency of experimental criteria, or laboratory artifacts could explain the discrepancy with previous reports. Further studies of the antibody response to the mid-gp41, AA 720-740, epitope are needed to resolve this issue.

Having documented that immunization of humans with certain rgp 160 vaccines may result in low titers of antibody to important antigenic structures and higher titers to possibly irrelevant epitopes, we should ask if the irrelevant response somehow suppresses the development of a more appropriate response? Several mechanisms could account for feedback inhibition of the antibody response. The regulation of the immune response by antibody to the antigen is a well-described phenomenon $(41,42)$. Alternatively, idiotype suppression could occur since anti-HIV antibodies to different viral structures have been shown to share a cross-reactive idiotype (43). This issue is of practical importance, since a vaccine construction lacking the mid-gp41 epitope might yield more neutralizing antibody.

The data presented in this paper suggest that the neutralizing antibody response obtained with these vaccination protocols fell short of a maximal response. Because we do not know what degree of immunity confers protection, we cannot say that these protocols are inadequate. Further refinements in immunization protocols may lead to antibody that more closely approximates the standard set by natural infection. It will be important to analyze systemic antibody responses resulting from immunization with other IIIB-based vaccine protocols in the manner described here. Of particular interest will be the results obtained following immunization with rgp 120 . This subunit lacks both the irrelevant mid-gp41 epitope and potential targets of enhancing antibody (33), and immunization with gp120, but not gp160, has been shown to prevent HIV infection of chimpanzees (6). Protocols combining priming with vaccinia-gp160 (or gp120) followed by boosting with soluble gp120 might also be tried.

The continuing rapid spread of AIDS through the developing world has led to a feeling of urgency in initiating vaccine efficacy trials (44). Such trials are likely to be costly, involve large control populations, and require long periods of observation before a vaccine effect can be demonstrated. It is imperative that any efficacy trial be performed with the most effective vaccination protocol(s). Intensive study of the in vitro correlates of immunity obtained in already ongoing small-scale vaccination protocols is needed to aid in choosing candidate vaccines for larger efficacy trials.

\section{Acknowledgments}

We admire the willingness of the anonymous laboratory workers who have been infected with HIV to allow themselves to be subjects of scientific investigation. However, no data derived from the study of these important patients can serve to mitigate the personal tragedies involved. 
We thank Bonnie Mathieson, Pat Fast, and Mary Clare Walker of the Division of AIDS, National Institute of Allergy and Infectious Diseases, for numerous helpful suggestions and information; Carol Smith of The EMMES Corporation and Ginga Colclough of Research Triangle Institute for coordinating clinical data and specimens; John Swanson, Brian Danneman, Thomas Matthews, and Robert Jones for review of this manuscript and thoughtful commentary; Scott Stewart for peptide synthesis; Gerald Spangrude for helping with flow cytometry; and Carole Smaus and Susan Smaus for word processing.

Our work was supported by NIAID and National Cancer Institute intramural funds, The National Institutes of Health Intramural AIDS Targeted Antiviral Program, contracts from the Division of AIDS, NIAID (NO1-AI 05062 and NO1-AI-05061) and by NIH grants AI25862 and NS-26665. These studies were performed in conjunction with the NIAID AIDS Vaccine Clinical Trials Network.

\section{References}

1. Cooney, E. L., A. C. Collier, P. D. Greenberg, R. W. Coombs, J. Zarling, D. E. Arditti, M. C. Hoffman, S.-L. Hu, and L. Corey. 1991. Safety of and immunological response to a recombinant vaccinia virus vaccine expressing HIV envelope glycoprotein. Lancet (N. Am. Ed.). 337:567-572.

2. Dolin, R., B. S. Graham, S. B. Greenberg, C. O. Tacket, R. B. Belshe, K Midthun, M. L. Clements, G. J. Gorse, B. W. Horgan, R. L. Atmar, D. T. Karzon, W. Bonnez, B. F. Fernie, D. C. Montefiori, D. M. Stablein, G. E. Smith, W. C. Koff, and NIAID AIDS Vaccine Clinical Trials Network. 1991. The safety and immunogenicity of a human immunodeficiency virus type 1 (HIV-1) recombinant gp 160 candidate vaccine in humans. Ann. Intern. Med. 114:119-127.

3. Redfield, R. R., D. L. Birx, N. Ketter, E. Tramont, V. Polonis, C. Davis, J. F. Brundage, G. Smith, S. Johnson, A. Fowler, T. Wierzba, A. Shafferman, F. Volvovitz, C. Oster, D. S. Burke, and Military Medical Consortium for Applied Retroviral Research. 1991. A phase I evaluation of the safety and immunogenicity of vaccination with recombinant gp 160 in patients with early human immunodeficiency virus infection. N. Engl. J. Med. 324:1677-1684.

4. Fultz, P. N., P. Nara, F. Barre-Sinoussi, A. Chaput, M. L. Greenberg, E. Muchmore, M.-P. Kieny, and M. Girard. 1992. Vaccine protection of chimpanzees against challenge with HIV-1-infected peripheral blood mononuclear cells. Science (Wash. DC). 256:1687-1690.

5. Girard, M., M.-P. Kieny, A. Pinter, F. Barre-Sinoussi, P. Nara, H. Kolbe K. Kusumi, A. Chaput, T. Reinhart, E. Muchmore, J. Ronco, M. Kaczorek, E. Gomard, J.-C. Gluckman, and P. N. Fultz. 1991. Immunization of chimpanzees confers protection against challenge with human immunodeficiency virus. Proc Natl. Acad. Sci. USA. 88:542-546.

6. Berman, P. W., T. J. Gregory, L. Riddle, G. R. Nakamura, M. A. Champe J. P. Porter, F. M. Wurm, R. D. Hershberg, E. K. Cobb, and J. W. Eichberg. 1990 Protection of chimpanzees from infection by HIV-1 after vaccination with recombinant glycoprotein gp120 but not gp 160. Nature (Lond.). 345:622-625.

7. Berman, P. W., J. E. Groopman, T. Gregory, P. R. Clapham, R. A. Weiss, R. Ferriani, L. Riddle, C. Shimasaki, C. Lucas, L. A. Lasky, and J. W. Eichberg. 1988. Human immunodeficiency virus type 1 challenge of chimpanzees immunized with recombinant envelope glycoprotein gp 120. Proc. Natl. Acad. Sci. USA 85:5200-5204

8. Emini, E. A., W. A. Schleif, J. H. Nunberg, A. J. Conley, Y. Eda, S. Tokiyoshi, S. D. Putney, S. Matsushita, K. E. Cobb, C. M. Jett, J. W. Eichberg, and K. K. Murthy. 1992. Prevention of HIV-1 infection in chimpanzees by gpl20 V3 domain-specific monoclonal antibody. Nature (Lond.). 355:728-730.

9. Fauci, A. S. 1991. Optimal immunity to HIV-natural infection, vaccination, or both? N. Engl. J. Med. 324:1733-1735.

10. Weiss, S. H., J. J. Goedert, S. Gartner, M. Popovic, D. Waters, P. Markham, F. di Marzo Veronese, M. H. Gail, W. E. Barkley, J. Gibbons, F. A. Gill, M. Leuther, G. M. Shaw, R. C. Gallo, and W. A. Blattner. 1988. Risk of human immunodeficiency virus (HIV-1) infection among laboratory workers. Science (Wash. DC). 239:68-71.

11. Adachi, A., H. E. Gendelman, S. Koenig, T. Folks, R. Willey, A. Rabson, and M. A. Martin. 1986. Production of acquired immunodeficiency syndromeassociated retrovirus in human and nonhuman cells transfected with an infectious molecular clone. J. Virol. 59:284-291.

12. Graham, B. S., R. B. Belshe, M. L. Clements, R. Dolin, L. Corey, P. F. Wright, G. J. Gorse, K. Midthun, M. C. Keefer, N. J. Roberts, Jr., D. H. Schwartz, J. M. Agosti, B. F. Fernie, D. M. Stablein, D. C. Montefiori, J. S. Lambert, S.-L. Hu, J. R. Esterlitz, D. N. Lawrence, W. C. Koff, and AIDS Vaccine Clinical Trials Network. 1992. Vaccination of vaccinia-naive adults with HIV-1 gp160 recombinant vaccinia (HIVAC-Ie) in a blinded, controlled, randomized clinical trial. J. Infect. Dis. 166:244-252.
13. Graham, B. S., T. J. Matthews, R. B. Belshe, M. L. Clements, R. Dolin, P. F. Wright, G. J. Gorse, D. H. Schwartz, M. C. Keefer, D. P. Bolognesi, L. Corey, D. M. Stablein, J. R. Esterlitz, S.-L. Hu, G. E. Smith, P. E. Fast, W. C. Koff, and NIAID AIDS Vaccine Clinical Trials Network. 1993. Augmentation of human immunodeficiency virus type 1 neutralizing antibody by priming with gp 160 recombinant vaccinia and boosting with rgp 160 in vaccinia naive adults. $J$. Infect. Dis. In press.

14. Chesebro, B., and K. Wehrly. 1988. Development of a sensitive quantitative focal assay for human immunodeficiency virus infectivity. J. Virol. 62:37793788.

15. Pincus, S. H., R. L. Cole, E. M. Hersh, D. Lake, Y. Masuho, P. J. Durda and J. McClure. 1991. In vitro efficacy of anti-HIV immunotoxins targeted by various antibodies to the envelope protein. J. Immunol. 146:4315-4324.

16. Gosting, L. H., J. McClure, E. S. Dickinson, S. M. Watanabe, K. Shriver, and L. C. Goldstein. 1987. Monoclonal antibodies to gp 110 and gp4l of human immunodeficiency virus. J. Clin. Microbiol. 25:845-848.

17. Posner, M. R., T. Hideshima, T. Cannon, M. Mukherjee, K. H. Mayer, and R. A. Byrn. 1991. An IgG human monoclonal antibody that reacts with HIV-1/gp120, inhibits virus binding to cells, and neutralizes infection. J. Immunol. 146:4325-4332

18. Geysen, H. M., S. J. Rodda, T. J. Mason, G. Tribbick, and P. G. Schoofs. 1987. Strategies for epitope analysis using peptide synthesis. J. Immunol. Methods. 102:259-274.

19. Myers, G., B. Korber, J. A. Berzofsky, R. F. Smith, G. N. Pavlakis, A. Gifford, J. Lawrence, R. Lenroot, and K. MacInnes. 1991. Human Retroviruses and AIDS 1991. A Compilation and Analysis of Nucleic Acid and Amino Acid Sequences. Los Alamos National Laboratory, Los Alamos, NM.

20. Pincus, S. H., K. Wehrly, and B. Chesebro. 1991. Use of a focal infectivity assay for testing susceptibility of HIV to antiviral agents. BioTechniques. 10:336342 .

21. Prince, A. M., B. Horowitz, L. Baker, R. W. Shulman, H. Ralph, J. Valinsky, A. Cundell, B. Brotman, W. Boehle, F. Rey, M. Piet, H. Reesink, N. Lelie, M. Tersmette, F. Miedema, L. Barbosa, G. Nemo, C. L. Nastala, J. S. Allan, D. R Lee, and J. W. Eichberg. 1988. Failure of a human immunodeficiency virus (HIV) immune globulin to protect chimpanzees against experimental challenge with HIV. Proc. Natl. Acad. Sci. USA. 85:6944-6948.

22. Rusche, J. R., K. Javaherian, C. McDanal, J. Petro, D. L. Lynn, R. Grimaila, A. Langlois, R. C. Gallo, L. O. Arthur, P. J. Fischinger, D. P. Bolognesi, S. D. Putney, and T. J. Matthews. 1988. Antibodies that inhibit fusion of human immunodeficiency virus-infected cells bind a 24-amino acid sequence of the viral envelope, gp120. Proc. Natl. Acad. Sci. USA. 85:3198-3202.

23. Javaherian, K., A. J. Langlois, C. McDanal, K. L. Ross, L. I. Eckler, C. L. Jellis, A. T. Profy, J. R. Rusche, D. P. Bolognesi, S. D. Putney, and T. J. Matthews. 1989. Principal neutralizing domain of the human immunodeficiency virus type 1 envelope protein. Proc. Natl. Acad. Sci. USA. 86:6768-6772.

24. Hwang, S. S., T. J. Boyle, H. K. Lyerly, and B. R. Cullen. 1991. Identification of the envelope $\mathrm{V} 3$ loop as the primary determinant of cell tropism in HIV-1. Science (Wash. DC) . 253:71-74.

25. Steimer, K. S., C. J. Scandella, P. V. Skiles, and N. L. Haigwood. 1991. Neutralization of divergent HIV-1 isolates by conformation-dependent human antibodies to gp 120. Science (Wash. DC). 254:105-108.

26. Xu, J.-Y., M. K. Gorny, T. Palker, S. Karwowska, and S. Zolla-Pazner. 1991. Epitope mapping of two immunodominant domains of gp4l, the transmembrane protein of human immunodeficiency virus type 1, using ten human monoclonal antibodies. J. Virol. 65:4832-4838.

27. Lasky, L. A., G. Nakamura, D. H. Smith, C. Fennie, C. Shimasaki, E. Patzer, P. Berman, T. Gregory, and D. J. Capon. 1987. Delineation of a region of the human immunodeficiency virus type $1 \mathrm{gp} 120$ glycoprotein critical for interaction with the CD4 receptor. Cell. 50:975-985.

28. Kennedy, R. C., R. D. Henkel, D. Pauletti, J. S. Allan, T. H. Lee, M. Essex, and G. R. Dreesman. 1986. Antiserum to a synthetic peptide recognizes the HTLV-III envelope glycoprotein. Science (Wash. DC). 231:1556-1559.

29. Chanh, T. C., G. R. Dreesman, P. Kanda, G. P. Linette, J. T. Sparrow, D. D. Ho, and R. C. Kennedy. 1986. Induction of anti-HIV neutralizing antibodies by synthetic peptides. EMBO (Eur. Mol. Biol. Organ.) J. 5:3065-3071.

30. Dalgleish, A. G., T. C. Chanh, R. C. Kennedy, P. Kanda, P. R. Clapham, and R. A. Weiss. 1988. Neutralization of diverse HIV-1 strains by monoclonal antibodies raised against a gp4l synthetic peptide. Virology. 165:209-215.

31. Evans, D. J., J. McKeating, J. M. Meredith, K. L. Burke, K. Katrak, A. John, M. Ferguson, P. D. Minor, R. A. Weiss, and J. W. Almond. 1989. An engineered poliovirus chimaera elicits broadly reactive HIV-1 neutralizing antibodies. Nature (Lond.). 339:385-388.

32. Broliden, P.-A., A. von Gegerfelt, P. Clapham, J. Rosen, E.-M. Fenyo, B. Wahren, and K. Broliden. 1992. Identification of human neutralization-inducing regions of the human immunodeficiency virus type 1 envelope glycoproteins. Proc. Natl. Acad. Sci. USA. 89:461-465.

33. Bolognesi, D. P. 1989. Do antibodies enhance the infection of cells by HIV? Nature (Lond.). 340:431-432. 
34. Horsfall, A. C., F. C. Hay, A. J. Soltys, and M. G. Jones. 1991. Epitope mapping. Immunol. Today. 12:211-213.

35. Javaherian, K., A. J. Langlois, G. J. LaRosa, A. T. Profy, D. P. Bolognesi, W. C. Herlihy, S. D. Putney, and T. J. Matthews. 1990. Broadly neutralizing antibodies elicited by the hypervariable neutralizing determinant of HIV-1. Science (Wash. DC). 250:1590-1593.

36. Palker, T. J., M. E. Clark, A. J. Langlois, T. J. Matthews, K. J. Weinhold R. R. Randall, D. P. Bolognesi, and B. F. Haynes. 1988. Type-specific neutralization of the human immunodeficiency virus with antibodies to env-encoded synthetic peptides. Proc. Natl. Acad. Sci. USA. 85:1932-1936.

37. Sun, N.-C., D. D. Ho, C. R. Y. Sun, R. S. Liou, W. Gordon, M. S. C. Fung, X.-L. Li, R. C. Ting, T.-H. Lee, N. T. Chang, and T.-W. Chang. 1989. Generation and characterization of monoclonal antibodies to the putative CD4-binding domain of human immunodeficiency virus type $1 \mathrm{gp} 120$. J. Virol. 63:3579-3585.

38. Ho, D. D., J. C. Kaplan, I. E. Rackauskas, and M. E. Gurney. 1988 Second conserved domain of gp 120 is important for HIV infectivity and antibody neutralization. Science (Wash. DC). 239:1021-1023.

39. Berkower, I., D. Murphy, C. C. Smith, and G. E. Smith. 1991. A predomi- nant group-specific neutralizing epitope of human immunodeficiency virus type 1 maps to residues 342 to 511 of the envelope glycoprotein gp120. J. Virol. 65:5983-5990.

40. Muster, T., F. Steindl, A. Buchacher, M. Purtscher, A. Trkola, G. Maiwald, G. Himmler, F. Ruker, A. Jungbauer, and H. Katinger. 1992. A conserved neutralizing epitope on gp4l of HIV-1. In 5th Annual Meeting of Advances in AIDS Vaccine Development. (Abstr.)

41. Hoffmann, M. K. 1980. Antibody regulates the cooperation of B cells with helper cells. Immunol. Rev. 49:79-91.

42. Chang, T. W. 1985. Regulation of immune response by antibodies: the importance of antibody and monocyte Fc receptor interaction in T-cell activation. Immunol. Today. 6:245-249.

43. Muller, S., H.-T. Wang, S. Kaveri, S. Chattopadhyay, and H. Kohler. 1991. Idiotype matching in AIDS by using monoclonal anti-idiotypic antibodies against human HIV-specific antibodies. In VII International Conference on AIDS. Science Challenging AIDS. Istituto Superiore di Sanita, Rome. 166. (Abstr.)

44. Cohen, J. 1991. AIDS vaccine meeting: International trials soon. Science (Wash. DC). 254:647. 